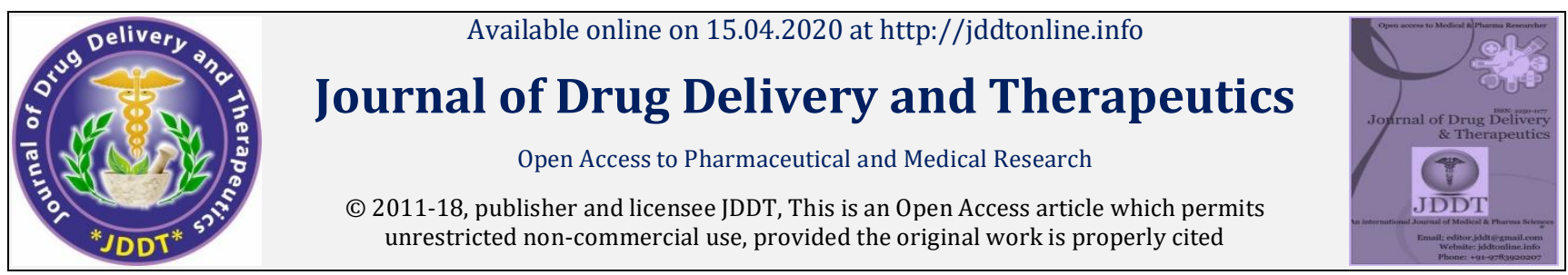

Open $\odot$ Access

Research Article

\title{
Formulation and In-Vitro Evaluation of Enteric Coated Tablet Incorporating Rabeprazole
}

\author{
Gautam D. Mehetre*1, Rameshwar S. Cheke'2, Vinayak N. Shrikhande ${ }^{2}$ \\ ${ }^{1}$ Department of Pharmaceutics, Dr. Rajendra Gode College of Pharmacy, Malkapur, Dist- Buldana, 443101 Maharashtra, India \\ 2 Department of Pharmaceutical Chemistry, Dr. Rajendra Gode College of Pharmacy, Malkapur, Dist- Buldana, 443101 Maharashtra, India
}

\begin{abstract}
The objective of the work is to try and assess the applicability and manufacturing possibilities to optimize an enteric coate d tablet formulation containing Rabeprazole sodium as the drug aiming at the anti-acidity activity with desired drug release properties. Enteric coated tablet was chosen as dosage form being a cost-effective technology for pharmaceutical industry requiring fewer procedures. Before the implementation of the pharmaceutical technological aims, analysis of critical factors influencing the manufacture was carried out. Reproducible manufacturing processes are required to achieve suitability and tablets uniformity to achieve the uniform properties of tablets, which could influence experimental parameters. Rabeprazole in core content of tablet is blended with HPMC (different grades), xanthan gum, PVPK30, mannitol, crosspovidone, Sodium starch glycolate, Colloidal silicon dioxide to formulate the product. Prepared formulation was tested for weight and content uniformity, physical characteristics, in vitro dissolution behaviour, acid resistance and accelerated stability studies. All studies performed resulted and revealed for assurance of such enteric coated tablet formulation for drug Rabeprazole with optimum characteristics, concluding it as a promising approach to enhance drug release characteristics.
\end{abstract}

Keywords: Rabeprazole, HPMC, enteric coated tablets, In Vitro evaluation.

Article Info: Received 28 Jan 2020; Review Completed 24 March 2020; Accepted 31 March 2020; Available online 15 April 2020

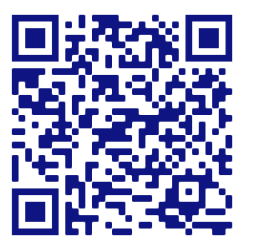

\section{Cite this article as:}

Mehetre GD, Cheke RS, Shrikhande VN, Formulation and In-Vitro Evaluation of Enteric Coated Tablet Incorporating Rabeprazole, Journal of Drug Delivery and Therapeutics. 2020; 10(2-s):50-57 http://dx.doi.org/10.22270/jddt.v10i2s.3953

Prof. G.D. Mehetre, Asst. Prof., Department of Pharmaceutics, Dr. Rajendra Gode College of Pharmacy, Malkapur, Dist- Buldhana, Pin code 443101, Maharashtra, India

\section{INTRODUCTION}

Oral site-specific drug delivery systems have attracted a great deal of interest recently for the local treatment of a variety of bowel diseases and also for improving systemic absorption of drugs, which are unstable in the stomach. However, the micro environment in the gastrointestinal tract and varying absorption mechanisms generally causes hindrance for the formulation scientist in the development and optimization of oral drug delivery. ${ }^{1}$ Delivery of therapeutic agent into the intestinal region could be accomplished by the application of an enteric coating on a solid dosage form. Several approaches have been attempted and reported during the last decade to develop new methodologies for site-specific drug release, including $\mathrm{pH}$ sensitive drug release and time-controlled drug release. Among these, the time-controlled release systems such as sustained or delayed-release dosage forms are very promising. Nevertheless, due to the potentially large variation of gastric emptying time of dosage forms in humans, these dosage form may show high inter patient variability in the site of drug delivery. On the other hand, $\mathrm{pH}$ - sensitive delivery systems such as enteric-coated dosage forms offer a simple and practical means for intestinal drug delivery. Rabeprazole sodium ${ }^{2}$ is a classical example of proton pump inhibitors and is approved by FDA for the treatment of symptomatic gastro esophageal reflux disease, long-term treatment and maintenance of erosive esophagitis. The stability of Rabeprazole sodium decreases with a corresponding decrease in the $\mathrm{pH}$ of the media. Hence, the exposure of Rabeprazole sodium to the acidic contents of the stomach would lead to significant degradation of the drug and would result in reduced bioavailability. Few attempts have been made to deliver this drug by peroral route in the form of enteric coated granules, solid dispersion, and suspension and matrix tablets. A number of enteric coating polymers are available and capable of protecting the drug core from the aggressive environments of the stomach. Being soluble at higher $\mathrm{pH}$ values, these polymers dissolve in the intestine and release the core for ready action. These polymers include several synthetic polymers like cellulose acetate phthalate (CAP), hydroxy propyl methyl cellulose phthalate (HPMCP). 
The aim of the present study was to compare the suitability of these renowned polymers to develop enteric coated tablets $^{3}$ of a very sensitive proton pump inhibitor Rabeprazole sodium. Rabeprazole sodium drug is a sodium salt of 2-((4-(3-methoxypropoxy)-3-methylpyridin-2-yl) methylsulfinyl) $-1 H$-benzo[d] imidazole belongs to a class of proton pump inhibitors (PPIs). It suppress surface of the gastric parietal cell. Enteric coated tablets are solid unit dosage forms meant for oral administration and are designed to bypass the stomach. 4

\section{MATERIALS AND METHODS}

Rabeprazole sodium is used as API in this study and was obtained as a gift sample from Incare Pharma Pvt. Ltd; hydroxy propyl methyl cellulose grade K15 and K100, xanthan gum, PVPK30, mannitol, crosspovidone, Sodium starch glycolate, Colloidal silicon dioxide are the other ingredients used for formulation of enteric coated tablets. Preliminary and optimization experiments have been carried out. Principal aim of the research work was the optimization of enteric coated tablet. The methods section contains all method descriptions, which were used either during preliminary or optimization studies.

\subsection{Pre-formulation Studies ${ }^{5,6}$}

The objective of pre-formulation studies is to develop a portfolio of information about the drug substance to serve as a set of parameters against which detailed formulation design can be carried out. Pre-formulation investigations are designed to identify those physicochemical properties of drug substances and excipients that may influence the formulation design, method of manufacture, and biopharmaceutical properties of the resulting product.

Analysis of lubricated compression blend for pre compression parameters such as angle of repose, bulk and tapped densities, compressibility index, and Hausner ratio was done according to the procedure stated for characterization of Rabeprazole.

\subsection{Fourier transforms infrared spectroscopy (FT-IR) interpretation $\mathbf{7 , 8 , 9 , 1 0}$}

The infrared spectrum of rabeprazole was recorded by using Perkin Elmer (Spectrum Bx) Fourier transform infrared spectroscopy. The sample was placed on the sample holder. The surface of the sample levelled. This sample holder was then placed in the analysis chamber and the spectrum was recorded.

\subsection{Formulation batches $11,12,13,14$}

Different formulation batches were formulated containing Rabeprazole as the active ingredient along with other suitable ingredients as tabulated below in table 1. Various blends tried were named as Batch B1 to B9.

Table 1. Formulation of core tablet

\begin{tabular}{|c|c|c|c|c|c|c|c|c|c|c|}
\hline S. No. & INGREDIENT & B1 & B2 & B3 & B4 & B5 & B6 & B7 & B8 & B9 \\
\hline 1. & Rabeprazole sodium & 20 & 20 & 20 & 20 & 20 & 20 & 20 & 20 & 20 \\
\hline 2. & HPMC K-100 & 20 & - & - & 30 & - & - & 15.5 & - & - \\
\hline 3. & HPMC K-15 & - & 20 & - & - & 30 & - & - & 15.5 & - \\
\hline 4. & Xanthan gum & - & - & 20 & - & - & 30 & - & - & 15.5 \\
\hline 5. & Mannitol & 60.4 & 60.4 & 60.4 & 50.4 & 50.4 & 50.4 & 65.4 & 65.4 & 65.4 \\
\hline 6. & Crospovidone & 30 & 30 & 30 & 30 & 30 & 30 & 30 & 30 & 30 \\
\hline 7. & Providone (PVP-K30) & 12 & 12 & 12 & 12 & 12 & 12 & 12 & 12 & 12 \\
\hline 8. & Talc & 0.5 & 0.5 & 0.5 & 0.5 & 0.5 & 0.5 & 0.5 & 0.5 & 0.5 \\
\hline 9. & Magnesium stearate & 5 & 5 & 5 & 5 & 5 & 5 & 5 & 5 & 5 \\
\hline 10. & Sodium starch glycolate & 1.5 & 1.5 & 1.5 & 1.5 & 1.5 & 1.5 & 1.5 & 1.5 & 1.5 \\
\hline 11. & Colloidal silicon dioxide & 1.5 & 1.5 & 1.5 & 1.5 & 1.5 & 1.5 & 1.5 & 1.5 & 1.5 \\
\hline
\end{tabular}

\subsection{Procedure of granulation 13 (For batches B1 - B9)}

Granules of the sustained release layer were formulated with dry granulation method using PVP K30 as granulating agent. Rabeprazole \& polymer were passed through $40 \#$ s.s. sieve. Mixed well for 15-20 minutes. PVP K30 was added to sufficient water under stirring to prepare granulating solution. This granulation solution was added to drug mixture till good wet mass was formed. This mass was passed through 8\# s.s. sieve. These granules were dried till LOD (loss on drying) was $2.0-2.5 \%$ and dried granules were passed through $20 \#$ sieve and the granules were lubricated with magnesium stearate and HPMC K-15, HPMC K100, Xanthum gum was also added in this step which were passed through $60 \#$ sieve prior to addition to granules.

Table 2. Formulation of enteric coated tablet

\begin{tabular}{|c|c|c|c|c|c|c|c|c|c|c|}
\hline S. No. & INGREDIENT & B1 & B2 & B3 & B4 & B5 & B6 & B7 & B8 & B9 \\
\hline 1. & HPMC-P & 7.6 & 7.6 & 7.6 & 7.6 & 7.6 & 7.6 & 7.6 & 7.6 & 7.6 \\
\hline 2. & Triethyl citrate (5\%) & 0.76 & 0.76 & 0.76 & 0.76 & 0.76 & 0.76 & 0.76 & 0.76 & 0.76 \\
\hline 3. & Isopropyl alcohol & q.s & q.s & q.s & q.s & q.s & q.s & q.s & q.s & q.s \\
\hline 4. & Dichloro- methane & q.s & q.s & q.s & q.s & q.s & q.s & q.s & q.s & q.s \\
\hline
\end{tabular}




\subsection{Procedure for preparation of sub-coating of the core tablets 12}

Sub coating of the compressed tablets is achieved by standard coating pan technique. Coating solutions of OPADRY prepared separately with plasticizers in $5 \%$ concentrations respectively. Thus solutions are applied over tablets using spray gun at appropriate pressure. The coated tablets are dried at $35-40{ }^{\circ} \mathrm{C}$ for $10 \mathrm{~min}$. $1 \%, 2 \%, 3 \%$, and $4 \%$ of sub coating percentage has been given to the core tablet.

\subsection{Procedure for preparation of enteric coating of the} sub-coated tablets 11

The sub coated tablets are loaded into containing bed is warmed till the temperature reaches to $38^{\circ} \mathrm{C}-40^{\circ} \mathrm{C}$. Then spray gun is switched on to spray the enteric coating dispersion using HPMC-P in more than $8 \%$ of enteric coating percentage has been given to the sub coated tablets.

\subsection{Evaluation of lubricated blends of formulations}

\subsubsection{Pre-compression parameters of tablet ${ }^{9}$}

Analysis of lubricated compression blend for precompression parameters such as angle of repose, bulk and tapped densities, compressibility index, and Hausner ratio was done according to the procedure stated for characterization of Rabeprazole sustained release tablets.

\subsubsection{Post-compression parameters $15,16,17,18$}

The tablet compacts were tested for Description, Thickness Hardness, Friability, Weight variation, Uniformity of drug content, In-vitro drug release of enteric coated tablets, Drug
Release Kinetic Studies, Accelerated Stability Studies. The results obtained are elaborated in the next section.

\section{RESULTS AND DISCUSSION}

\subsection{Pre-formulation study of the drug}

The flow property study of blend of all ingredients along with drug was carried out \& all the parameters obtained within a range.

Table 3. Micromeretic properties of API

\begin{tabular}{|c|c|c|}
\hline S. No. & Characteristics & Results \\
\hline 1 & Description & $\begin{array}{c}\text { Of white to pale yellow colour } \\
\text { amorphous powder }\end{array}$ \\
\hline 2 & Bulk Density & $0.53 \mathrm{gm} / \mathrm{ml}$ \\
\hline 3 & Tapped Density & $0.69 \mathrm{gm} / \mathrm{ml}$ \\
\hline 4 & Carr's Index & $32.1 \%$ \\
\hline 5 & Hausner Ratio & 4.17 \\
\hline 6. & Angle of Response & 36 \\
\hline
\end{tabular}

\subsection{Compatibility Study}

The results of FTIR analysis of pure drug and bend of drug with polymers used for the formulations were interpreted and revealed that there is no significant interaction between drug and polymers. This is an assuring result to use these ingredients with no alteration in physicochemical as well as therapeutic activity of the formulation. The Rabeprazole FTIR alone and in blend is presented as below in figures 1 to 4.

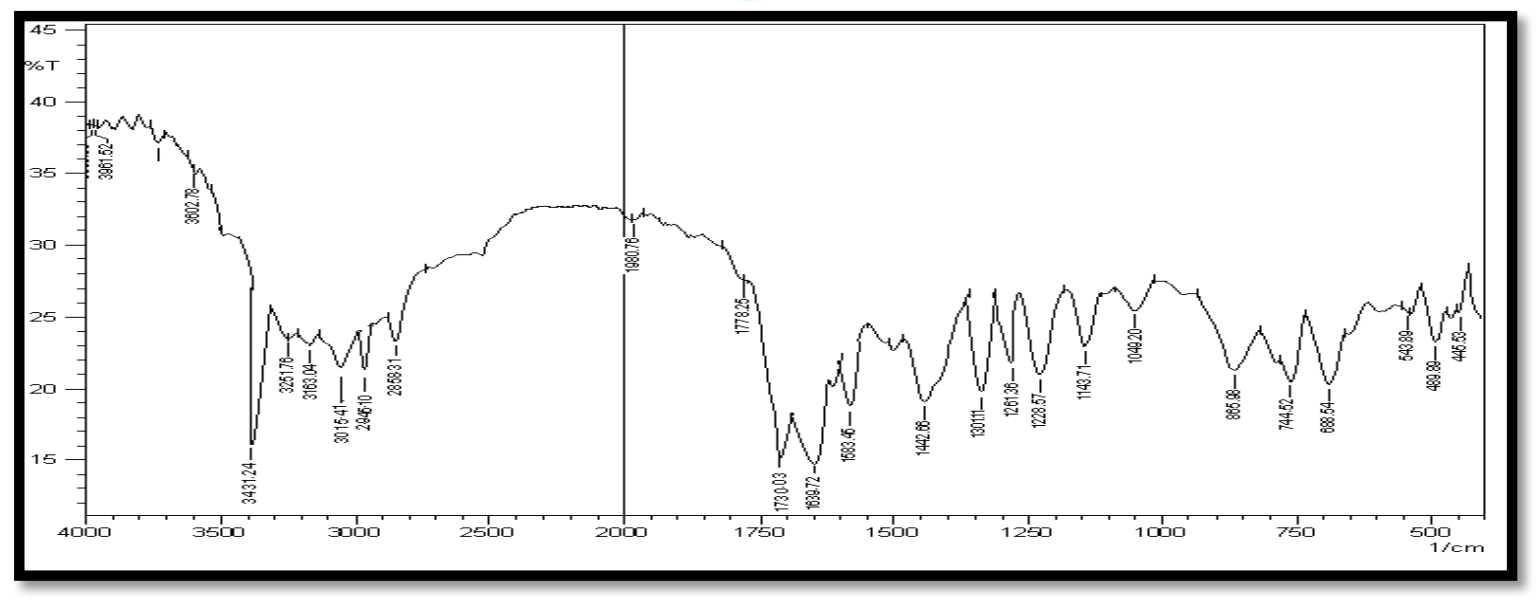

Fig. 1 FT-IR of Rabeprazole

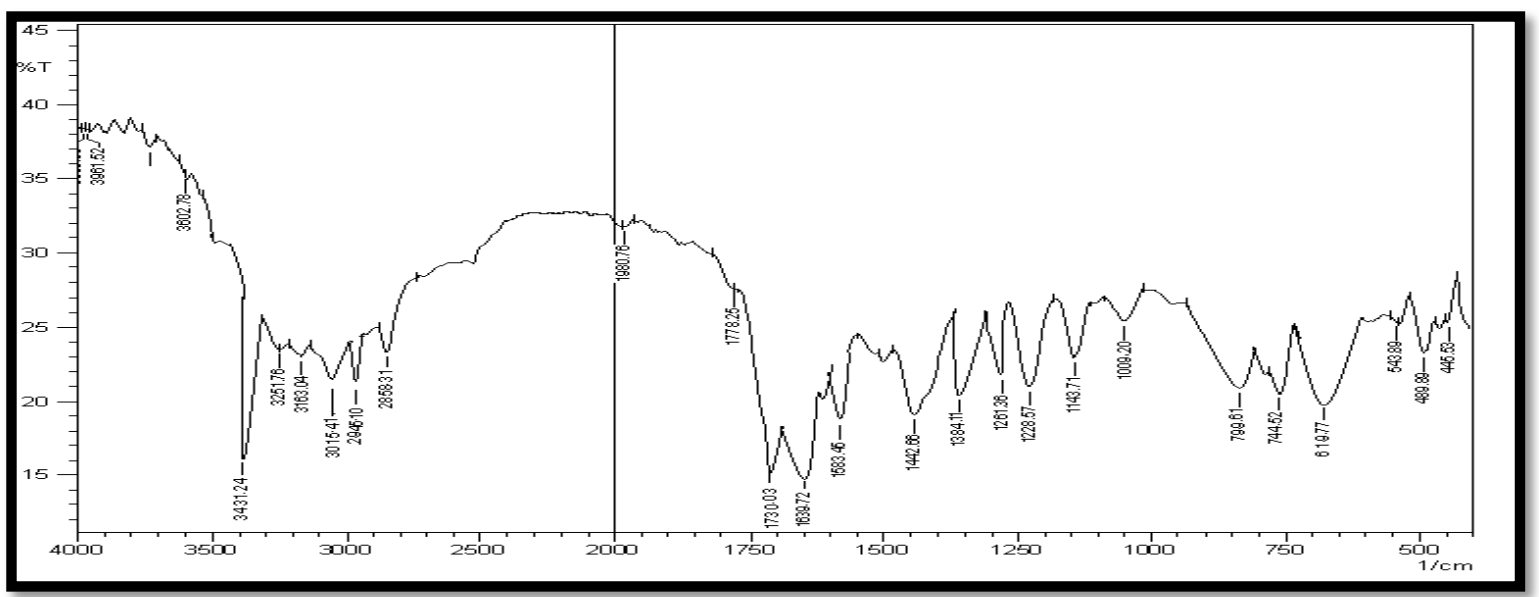


Fig. 2 FT-IR of Rabeprazole with HPMC K100

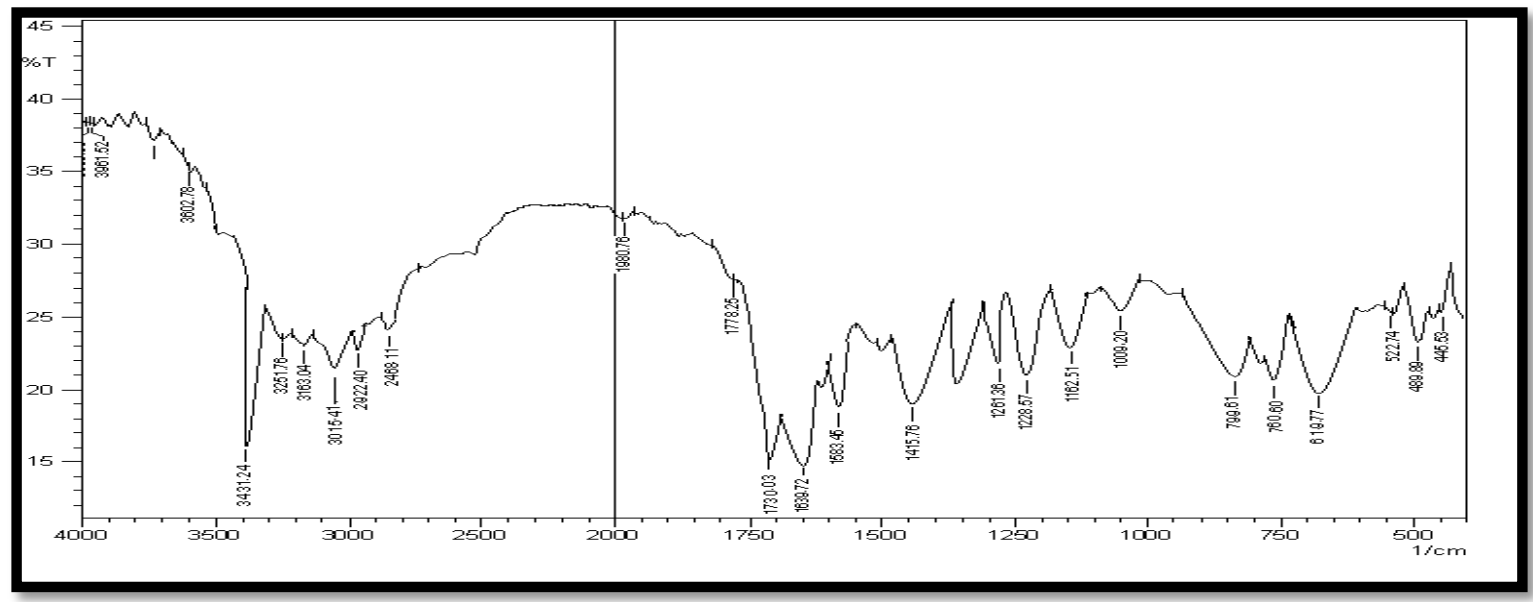

Fig. 3 FT-IR of Rabeprazole with xanthan gum

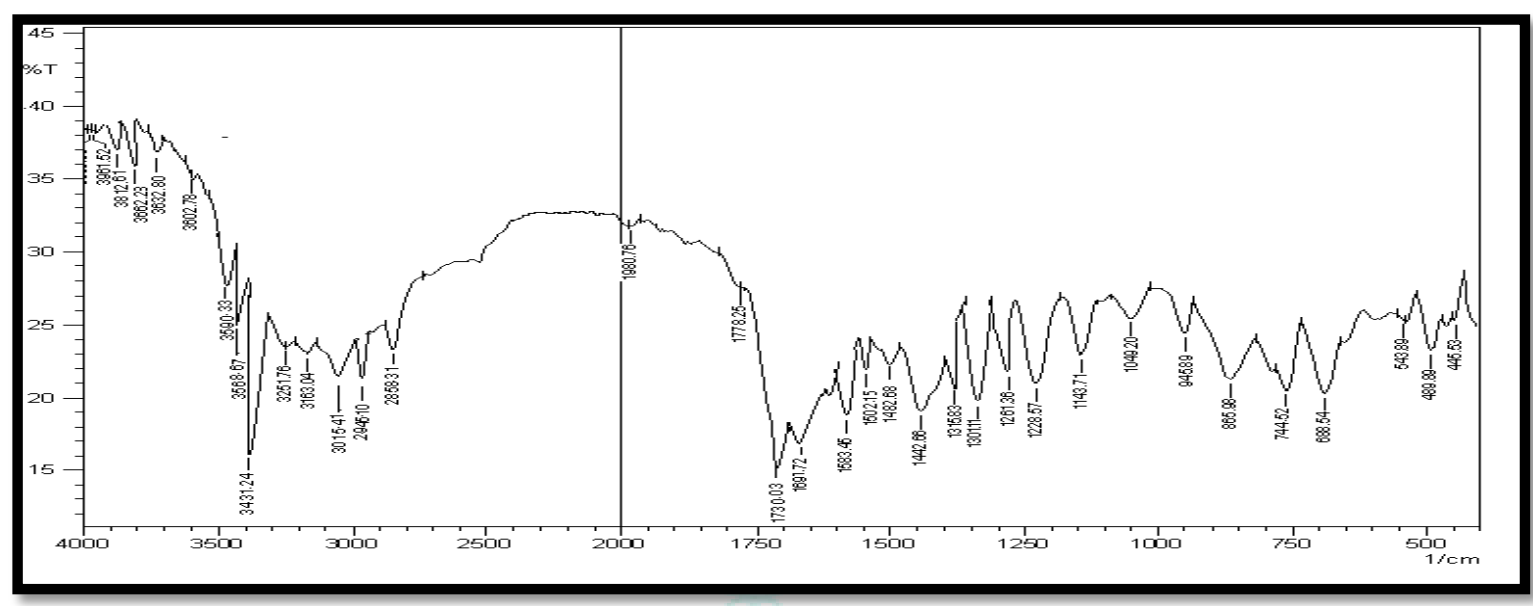

Fig. 4 FT-IR of Rabeprazole with HPMC K-15

\subsection{Post Compressional evaluation of prepared tablets}

Formulation batches B1 to B9 were evaluated for post compressional parameters such as Weight, Thickness,
Hardness, Friability and the results found are as tabulated below in table 4. Results obtained of all formulation within range as per official standard.

Table 4. Characteristics of formulation

\begin{tabular}{|c|c|c|c|c|}
\hline $\begin{array}{c}\text { Formulation } \\
\text { Batch }\end{array}$ & $\begin{array}{c}\text { Average wt (mg) } \\
\pm \text { (SD) }\end{array}$ & $\begin{array}{c}\text { Thickness (m) } \\
\pm \text { (SD) }\end{array}$ & $\begin{array}{c}\text { Hardness (kp) } \\
\pm \text { (SD) }\end{array}$ & $\begin{array}{c}\text { Friability } \\
\pm \text { (SD) }\end{array}$ \\
\hline B1 & $151.2 \pm 5.16$ & $4.0 \pm 0.08$ & $6-8 \pm 0.18$ & $0.75 \pm 0.08$ \\
\hline B2 & $149.5 \pm 5.11$ & $4.1 \pm 0.08$ & $6-8 \pm 0.18$ & $0.75 \pm 0.08$ \\
\hline B3 & $150.6 \pm 5.09$ & $4.0 \pm 0.07$ & $6-8 \pm 0.28$ & $0.64 \pm 0.08$ \\
\hline B4 & $151.4 \pm 5.12$ & $4.0 \pm 0.08$ & $6-8 \pm 0.18$ & $0.75 \pm 0.08$ \\
\hline B5 & $144 \pm 5.15$ & $4.1 \pm 0.08$ & $6-8 \pm 0.22$ & $0.60 \pm 0.08$ \\
\hline B6 & $152.6 \pm 5.16$ & $4.1 \pm 0.08$ & $6-8 \pm 0.23$ & $0.65 \pm 0.08$ \\
\hline B7 & $150 \pm 5.17$ & $4.0 \pm 0.08$ & $6-8 \pm 0.31$ & $0.71 \pm 0.08$ \\
\hline B8 & $145 \pm 5.12$ & $4.0 \pm 0.08$ & $6-8 \pm 0.23$ & $0.74 \pm 0.08$ \\
\hline B9 & $149 \pm 5.10$ & $4.0 \pm 0.08$ & $6-8 \pm 0.33$ & $0.75 \pm 0.08$ \\
\hline
\end{tabular}




\subsection{Acid resistance test 19}

To determine the effect of gastric environment the acid resistance study was carried out. All the formulation showed resistance to acid. Formulations maintained their integrity in simulated gastric fluid. The formulations didn't disintegrate up to $45 \mathrm{~min}$ as per the official standard.

Table 5. Acid resistance test

\begin{tabular}{|c|c|c|c|c|c|c|c|c|c|}
\hline Batch & B1 & B2 & B3 & B4 & B5 & B6 & B7 & B8 & B9 \\
\hline Acid resistance (\%) & 100 & 95 & 98 & 93 & 99.5 & 90 & 98.8 & 80 & 97 \\
\hline $\begin{array}{c}\text { Disintegration of tablet in acid } \\
\text { 0.1 N HCL(1hr) }\end{array}$ & NO & NO & NO & NO & NO & NO & NO & NO & NO \\
\hline
\end{tabular}

\subsection{In vitro Dissolution tests ${ }^{20,21,22}$}

The dissolution for all the formulations was carried out according to US Pharmacopoeia for $2 \mathrm{~h}$ in $0.1 \mathrm{~N} \mathrm{HCl}$ and then media was changed into phosphate buffer of $\mathrm{pH}$ 6.8. The temperature was maintained at $37 \pm 0.5^{\circ} \mathrm{C}$ and a constant paddle rotation speed of $100 \mathrm{rpm}$. The formulation B1 showed more percentage drug release (99.5\%) as compared with other formulation. All the formulations showed optimum drug release as per the criteria of sustained drug release. From the results of the present study experiment, it was concluded that by using the combination of HPMC K15 and HPMC K100, one can obtain the good control on the release profile of water soluble drug and sustained release formulation can be successfully prepared. HPMC K100 hydrates and forms gel at a higher rate as compared to HPMC K15 and is helpful for initially controlling the release rate of water soluble Rabeprazole sodium drug.

Table 6 depicts results of in vitro dissolution test. The in vitro drug release profiles B1 to B9 are diagrammed below in figures 5 to 7 .

Table 6. In vitro drug release from the formulations B1 to B9

\begin{tabular}{|c|c|c|c|c|c|c|c|c|c|}
\hline $\begin{array}{c}\text { In vitro drug release from } \\
\text { the formulation after } \\
\text { time(hrs) }\end{array}$ & $\mathbf{B 1}$ & $\mathbf{B 2}$ & $\mathbf{B 3}$ & $\mathbf{B 4}$ & $\mathbf{B 5}$ & $\mathbf{B 6}$ & $\mathbf{B 7}$ & $\mathbf{B 8}$ & $\mathbf{B 9}$ \\
\hline 0 & 00 & 00 & 00 & 00 & 00 & 00 & 00 & 00 & 00 \\
\hline 1 & 5.3 & 5.22 & 5.21 & 5.2 & 5.18 & 5.21 & 5.21 & 5.21 & 5.21 \\
\hline 1.30 & 20 & 15 & 10 & 16 & 13 & 12 & 13 & 16 & 14 \\
\hline 2 & 35.1 & 31 & 27 & 30 & 25 & 21 & 30 & 24 & 25 \\
\hline 3 & 46.96 & 40.05 & 35.35 & 39 & 33.65 & 30 & 40 & 38 & 35 \\
\hline 4 & 56.17 & 49.81 & 46.08 & 50 & 42 & 37 & 55 & 53 & 51 \\
\hline 5 & 65.8 & 58 & 53.66 & 59 & 51 & 45 & 60 & 63.66 & 63.66 \\
\hline 6 & 74 & 65 & 60.89 & 67 & 58 & 53 & 70.89 & 70.89 & 70.89 \\
\hline 7 & 80 & 71 & 70.3 & 71 & 64 & 60 & 73 & 75.3 & 73 \\
\hline 8 & 87.4 & 78 & 76 & 76 & 68 & 70 & 80 & 82.21 & 81 \\
\hline 9 & 91 & 83 & 80 & 80 & 73 & 79 & 82 & 86.29 & 86.29 \\
\hline 10 & 94 & 85.7 & 85 & 83 & 80 & 84 & 85 & 90 & 88.29 \\
\hline 11 & 97 & 91 & 90.1 & 88 & 85.25 & 88 & 90.1 & 95 & 90.1 \\
\hline 12 & 99.5 & 95.2 & 93.2 & 92 & 91 & 89 & 96.7 & 98.1 & 96.7 \\
\hline
\end{tabular}

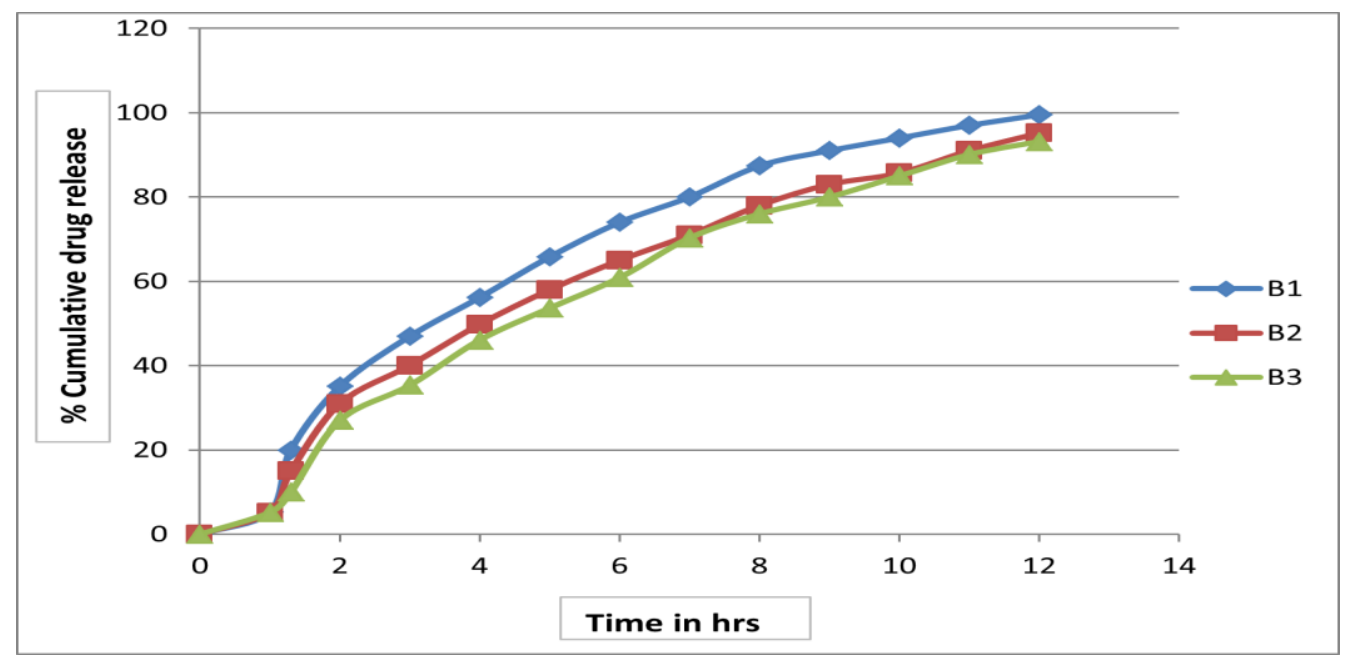

Fig. 5 In vitro drug release profile of batches (B1-B3) 


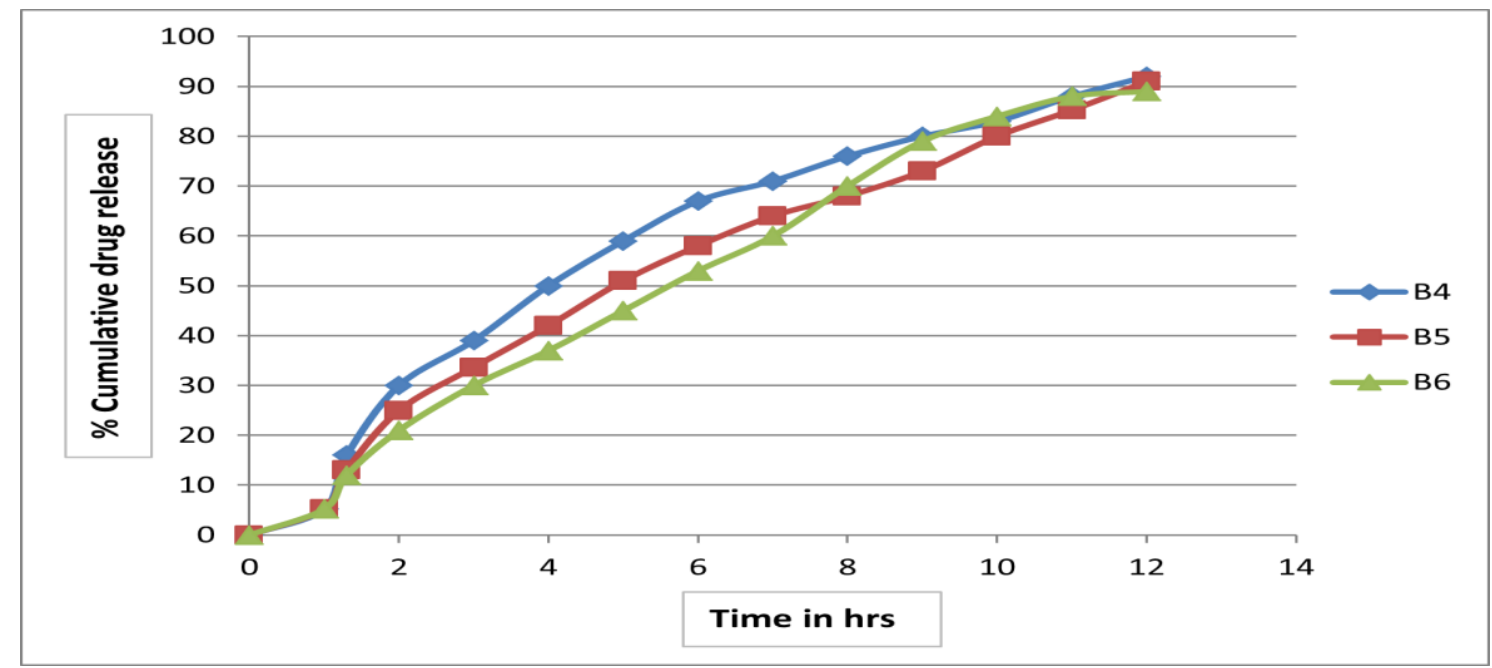

Fig. 6 In vitro drug release profile of batches (B4-B6)

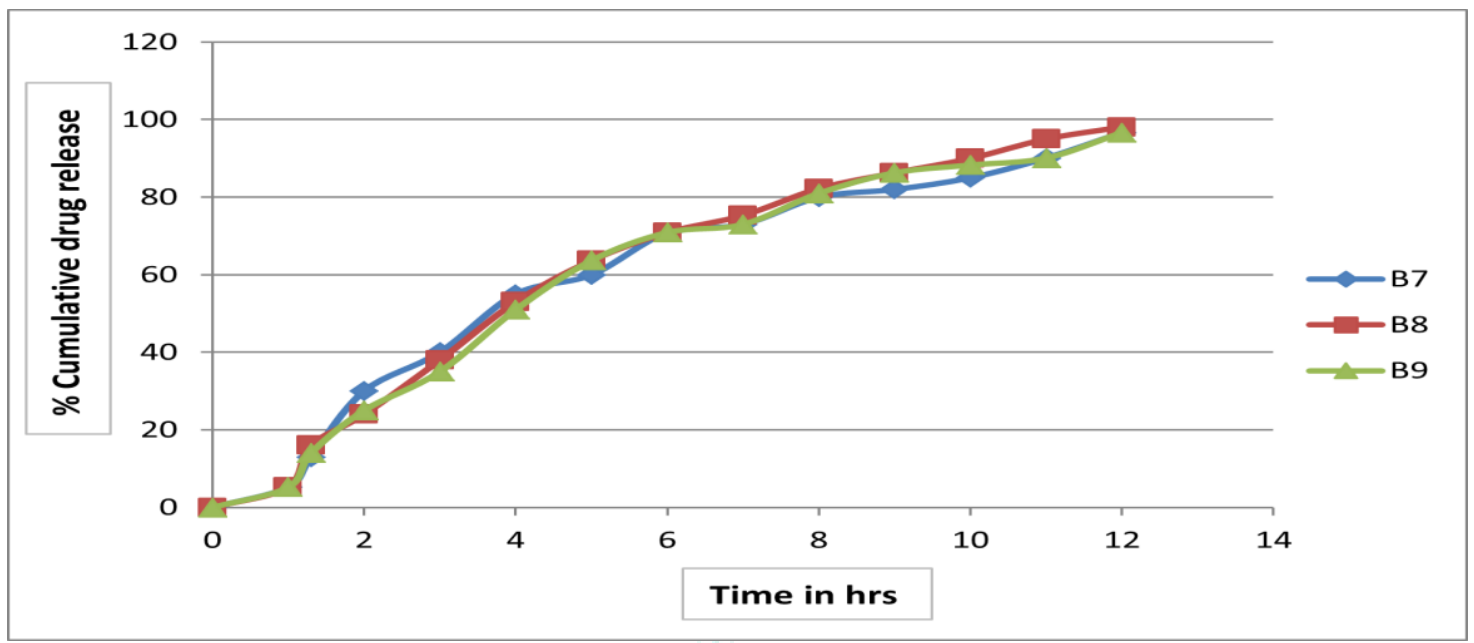

Fig. 7 In vitro drug release profile of batches (B7-B9)

\subsection{Stability study ${ }^{23,24}$}

In the present study, stability studies were carried out at 40 $\pm 2{ }^{\circ} \mathrm{C} / 75 \pm 5 \% \mathrm{RH}$ for a specific time period up to 1 month The tablets from the selected and optimized batch (B-1) were studied for stability and kept under the accelerated conditions of temperature and moisture (humidity) for the period of one month. Each tablet was individually weighed and packed in high-density polyethylene (HDPE) containers and put at above specified conditioned in a Stability chamber for one month. After one month, the formulation was observed for changes in physical appearance and chemical analysis. The optimized formulation B1 showed very good drug release behaviour even after undergoing accelerated stability studies which conformed to its optimum nature. Data is tabulated in table 7.

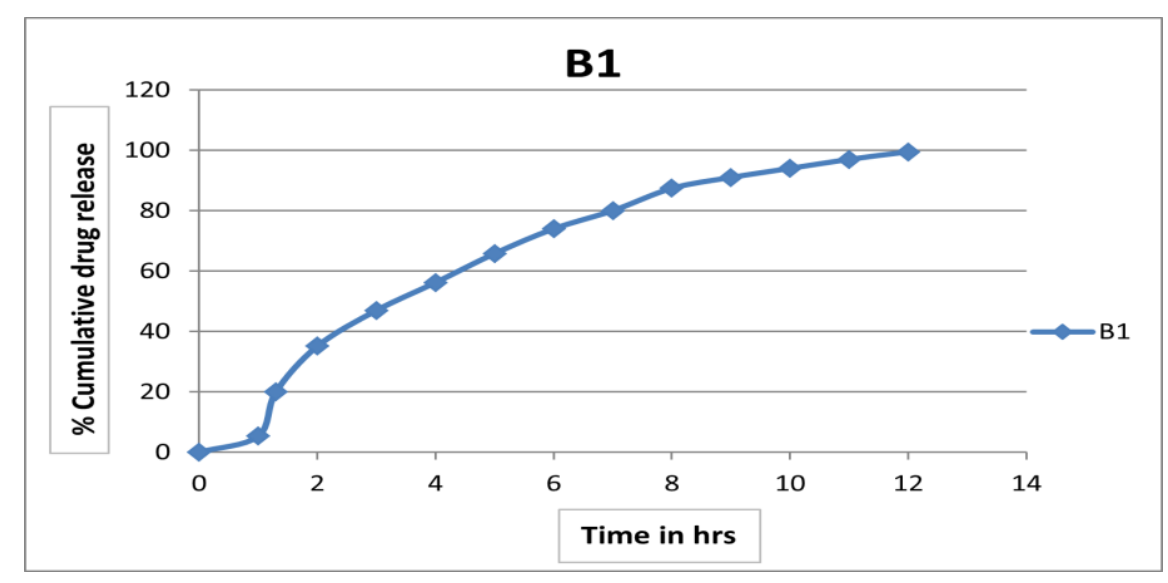

Fig. 8 Stability study curve 
Table 7. Stability study of optimized batch (B1) in intestine PH (7.5)

\begin{tabular}{|c|c|c|c|}
\hline Sampling time (Hr) & Colour change & Thickness & Change in integrity \\
\hline 0 & No & 4.1 & No \\
\hline 2 & No & 4.3 & No \\
\hline 4 & No & 4.7 & No \\
\hline 6 & No & 4.8 & No \\
\hline 8 & No & 4.10 & No \\
\hline 10 & No & 4.13 & 4.15 \\
\hline 12 & No & & \\
\hline
\end{tabular}

\subsection{Drug Release Kinetic Studies}

To analyse the mechanism of drug release from the tablets, in vitro dissolution data were fitted in Zero Order, First
Order, Matrix Model, Korsemeyer-Peppas Model. The results are as tabulated below in table 8.

Table 8. Drug Release Kinetic Studies

\begin{tabular}{|c|c|c|c|c|}
\hline $\begin{array}{c}\text { Formulation Batch } \\
\text { (Optimized) }\end{array}$ & $\begin{array}{c}\text { Zero Order } \\
\mathbf{( R}^{\mathbf{2}}\end{array}$ & $\begin{array}{c}\text { First Order } \\
\left.\mathbf{( R}^{2}\right)\end{array}$ & $\begin{array}{c}\text { Higuchi Model } \\
\mathbf{( R}^{\mathbf{2}} \mathbf{)}\end{array}$ & $\begin{array}{c}\text { Korsemeyer- } \\
\text { Peppa's Model (n) }\end{array}$ \\
\hline B1 & 0.9088 & 0.9612 & 0.9901 & 0.5345 \\
\hline
\end{tabular}

The batch B1 is optimized in that $\mathbf{R}^{\mathbf{2}}$ values were higher for Higuchi model than for zero order model indicating that the drug release from the formulation followed Higuchi model, indicating that the drug release mechanism from the tablet was diffusion controlled. Obtained values of $\mathbf{n}$ is 0.5345 indicating non-fickian release kinetic, which is indicating of drug release mechanism involving, diffusion mechanism. Therefore, the release of drug from the prepared tablet is controlled by swelling of polymers followed by drug diffusion through the swelled polymer.

\section{CONCLUSION}

In the above view of findings it can be concluded that hydroxypropylmethylcellulose of grade K100M when combined with the grade K15M shows the desired sustained release effect and hence can be utilized as matrix forming agent to prolong the release of Rabeprazole. The overall frequency of administration of a drug candidate like Rabeprazole was successfully reduced, which generally requires dosing in 3 to 4 times a day in conventional tablet dosage form. Thus the improved patient compliance might be obtained by the administration of such a dosage form with the reduced dosing frequency and of attractive appearance. The release retardant materials are economical, readily available, safe, having wide regulatory acceptance and easy to handle. It may be beneficial to adopt such a technology for the commercial production of enteric coated sustained release tablet.

From the results of the present study experiment, it was concluded that by using the combination of HPMC K15M and HPMC K100M, one can obtain the good control on the release profile of water soluble drug and sustained release formulation can be successfully prepared. HPMC K100M hydrates and forms gel at a higher rate as compared to HPMC $\mathrm{K} 15 \mathrm{M}$ and is helpful for initial controlling the release rate of water soluble Rabeprazole sodium drug. In all formulations, batch B1 shows better drug release (99.5\%) in which polymer HPMC K100M -20mg is added.

\section{REFERENCES}

1. Robinson JR, Lee VH, In: Controlled Drug Delivery Fundamentals and Applications, Marcel Dekker, INC, New York, 1987; Vol. 29, 2nd edition, 4-6.

2. Tripathi KD, Pharmacological classification of drugs, $2005 ; 3^{\text {rd }}$ edition, 18.

3. Swarbrick J, Encyclopaedia of Pharmaceutical Technology, Vol.1, $3^{\text {rd }}$ edition, 1248-1250.

4. Fukui E, Miyamura N, Uemura K et al. Preparation of entericcoated timed-release press-coated tablets and evaluation of their function by in vitro and in vivo tests for colon targeting, International Journal Pharmaceutics, 2000; 204, 7-15.

5. Yong CS, Jung JH, Rhee JD, Kook KC, Choi HG, Preformulation studies of tablets, Drug Development in Industrial Pharmacy, 2001; 27(5): 447-455.

6. Sweetman SC, Martindale- The Complete Drug Reference, Pharmaceutical Press, Landon, 2005; 256-258.

7. Hunt RH, Armstrong D, Yaghoobi M, James C, The pharmacodynamics and pharmacokinetics of S-tenatoprazole-Na $30 \mathrm{mg}, 60 \mathrm{mg}$ and $90 \mathrm{mg}$ vs. Esomeprazole $40 \mathrm{mg}$ in healthy male subjects, Aliment Pharmacology Therapy, 2010; 31:648657.

8. Raymond CR, Paul JS, Quinn ME, Hand Book of Pharmaceutical Excipients, Pharmaceutical Press, Washington D.C., 2009; $6^{\text {th }}$ edition, 581-585.

9. Raymond CR, Paul JS, and Quinn ME, Hand Book of Pharmaceutical Excipients, Pharmaceutical Press, Washington D.C., 2009; $6^{\text {th }}$ edition, 404-407.

10. Remington's Pharmaceutical Sciences, The Science and Practice of Pharmacy, Mack Publishing Company, Vol. 1, 19 th edition, 1669-1670.

11. Hoogerwerf WA, Pasricha PJ, In: Hardman, JG, Limbird LE, Molinoff PB, Ruddon RW, Gilman AG, (Eds.), Goodman \& Gilman's The Pharmacological Basis of Therapeutics, International Publication McGraw Hill, New York, 1996; 10071009.

12. Lachman L, Liberman HA, Kanig JL, The Theory and Practice of Industrial Pharmacy, $3^{\text {rd }}$ edition, $3^{\text {rd }}$ Indian Reprint, Varghese Publishing House, Bombay, 1990; 316-317.

13. Laine L, Katz PO, Johnson DA, et al. Randomised clinical trial: a novel rabeprazole extended release $50 \mathrm{mg}$ formulation vs. esomeprazole $40 \mathrm{mg}$ in healing of moderate-to-severe erosive 
esophagitis - the results of two double-blind studies, Aliment Pharmacology Therapy, 2011; 33:203-212.

14. Brirish Pharmacopoeia, Volume III, 2009; Formulated Preparations: Specific monographs, Tablets, 1.

15. Biswas BK, Islam S, Begum F, et al. In vitro release kinetic study of esomeprazole magnesium from methocel $\mathrm{K} 15 \mathrm{M}$ and methocel K100M LVCR matrix tablets, Dhaka University Journal of Pharmaceutical Sciences, 2008; 7:39-45.

16. Murthy KS, Kubert DA, Fawzi MB, In vitro release characteristics of hard shell capsule products coated with aqueous- and organic-based enteric polymers, Journal of Biomater Applications, 1988; 3:52-79.

17. Sinha VR, Kumria R, Coating polymers for colon specific drug delivery: A comparative in vitro evaluation, Acta Pharma, 2003; 53:41-47.

18. Johnson DA, Review of esomeprazole in the treatment of acid disorders, Expert Opinions in Pharmacotherapy, 2003; 4:253264.

19. Katz PO, Ginsberg GG, Hoyle PE, Sostek MB, Monyak JT, Silberg DG, Relationship between intragastric acid control and healing status in the treatment of moderate to severe erosive esophagitis, Aliment Pharmacology Therapy, 2007; 25:617-628.

20. Yuan Y, Hunt RH, Rabeprazole extended release $50 \mathrm{mg}$ compared with esomeprazole $40 \mathrm{mg}$ and rabeprazole delayed release 20 mg, Aliment Pharmacology Therapy, 2011; 33:1177.

21. Morelli G, Chen H, Rossiter G, Rege B, Lu Y, An open-label, parallel, multiple- dose study comparing the pharmacokinetics and gastric acid suppression of rabeprazole extended release with esomeprazole $40 \mathrm{mg}$ and rabeprazole delayed-release 20 mg in healthy volunteers, Aliment Pharmacology Therapy, 2011; 33:845-854

22. Aulton ME, Pharmaceutics: The Science of Dosage form design, Churchill Livingstone, England, 2002; 2 $2^{\text {nd }}$ edition, 247.

23. Jain R, Jindal C, Singh S, Pharmaceutical composition comprising of proton pump inhibitor and prokinetic agent, U. S. Patent No 2007/0160664A1, 2007.

24. Aoki S, Preparation, composition containing acid unstable physiologically active compound and process for producing same, U. S. Patent No. US 2005/0163846 A1, 2005. 